\title{
New Developments and Insights in the Improvement of Mycobacterium tuberculosis Vaccines and Diagnostics Within the End TB Strategy
}

\author{
Juan Ignacio García ${ }^{1}$ (D) - Anna Allué-Guardia ${ }^{1} \cdot$ Radhika P. Tampi $^{2} \cdot$ Blanca I. Restrepo $^{3,4} \cdot$ Jordi B. Torrelles $^{1}(\mathbb{D})$
}

Accepted: 25 March 2021 / Published online: 7 April 2021

(C) The Author(s), under exclusive licence to Springer Nature Switzerland AG 2021

\begin{abstract}
Purpose of review The alignment of sustainable development goals (SDGs) with the End Tuberculosis (TB) strategy provides an integrated roadmap to implement key approaches towards TB elimination. This review summarizes current social challenges for TB control, and yet, recent developments in TB diagnosis and vaccines in the context of the End TB strategy and SDGs to transform global health.

Recent findings Advances in non-sputum based TB biomarkers and whole genome sequencing technologies could revolutionize TB diagnostics. Moreover, synergistic novel technologies such as mRNA vaccination, nanovaccines and promising TB vaccine models are key promising developments for TB prevention and control.

Summary The End TB strategy depends on novel developments in point-of-care TB diagnostics and effective vaccines. However, despite outstanding technological developments in these fields, TB elimination will be unlikely achieved if TB social determinants are not fully addressed. Indeed, the End TB strategy and SDGs emphasize the importance of implementing sustainable universal health coverage and social protection.
\end{abstract}

Keywords End TB strategy $\cdot$ Sustainable development goals $\cdot$ TB diagnosis $\cdot$ Vaccines

\section{Introduction}

The tuberculosis (TB) pandemic, caused by the airborne pathogen Mycobacterium tuberculosis (M.tb), killed more than 1.2

This article is part of the Topical Collection on Infectious Disease Epidemiology

Juan Ignacio García

juangarcia@txbiomed.org

$\triangle$ Jordi B. Torrelles

jtorrelles@txbiomed.org

1 Population Health Program, Tuberculosis Group, Texas Biomedical Research Institute, 8715 W. Military Dr, San Antonio, TX 78227, USA

2 PhD Program in Health Policy, Harvard University, Cambridge, MA 02138, USA

3 University of Texas Health Science Center at Houston, School of Public Health, Brownsville, TX 78520, USA

4 School of Medicine, South Texas Diabetes and Obesity Institute, University of Texas Rio Grande Valley, Edinburg, TX 78539, USA million people in 2019 with $75 \%$ of the TB cases occurring in South-East Asia and Africa [1]. TB strongly impacts the daily life of infected individuals and their household contacts, and results in catastrophic health and economic costs $[2,3]$. TB burden affects mostly countries with fragile and overwhelmed health care systems that need to be strengthened accordingly in order to improve linkage and retention in TB treatment and care, while reducing direct and indirect TB treatment costs [4, $5]$.

The emergence of drug-resistant TB (DR-TB) and the synergy between TB and other communicable and noncommunicable chronic diseases such as HIV/AIDS and diabetes or malnutrition, respectively, are also posing an increasing challenge to TB prevention and control strategies, as globalization, demographics, and lifestyle changes, including alcohol and tobacco consumption, are fuelling TB expansion worldwide [1].

Current public health efforts and resources are shifting towards controlling the coronavirus disease 2019 (COVID-19) pandemic. This deviation of resources is undermining TB prevention and control, and is estimated to worsen TB 
transmission dynamics, treatment outcomes, and diagnosis. The implicated factors include reduced health care access, deviation of economic and human resources, fear, stigma, and the overlap between COVID-19 and TB clinical symptoms, among others [6, 7]. A modeling study from The STOP TB Partnership and collaborators evaluating the effects of COVID-19 lockdowns, estimates an additional 6.3 millon TB cases and 1.4 million TB deaths globally during the 2020-2025 period, bringing TB incidence and TB deaths " $t o$ levels last seen in 2013 and 2016, respectively" [8].

Neverthless, the End TB strategy adopted by the World Health Organization (WHO) in 2015 aims to end the global TB pandemic under ambitious milestones and targets to be achieved by the end of 2035 [9]. The End TB strategy was built in parallel to the sustainable development goals (SDGs) [10], which expands upon the successes of the Millennium Development Goals (MDGs) [11]. The mission of the seventeen SDGs is to transform our world by 2030 by focusing on sustainable development to erradicate poverty and achieve human rights for all while incorporating improved health outcomes [12].

In this review, we discuss major challenges to TB control and prevention as well as recent advances in $\mathrm{TB}$ vaccines and diagnostics within the context of the End TB strategy (specifically focussing on Pillar 1 key components ' $A$ ' and ' $D$ ') and the SDGs.

\section{Methods}

We performed a comprehensive literature review within the period 2015-2020. Key review papers and outstanding original research papers older than this period were also included when its scientific relevance was salient to the scope of this review. Searches were performed in May 2020 in the PubMed database for articles containing in the title and/or abstract the following terms: "tuberculosis" and ("vaccines," or "diagnosis," or "communicable diseases," or "syndemics," or "non communicable diseases," or "sustainable development goals," or "End TB strategy"). This search resulted in 217 papers that were further evaluated for their relevance. Of these, we included 13 articles in the section of major drivers of TB expansion, 27 articles in the section describing the End TB strategy and SDGs, 36 articles to discuss TB diagnostics, and 41 articles to discuss TB vaccines.

\section{Major Drivers of TB Expansion}

TB elimination efforts face three major challenges: First, the increasing prevalence of DR-TB including isoniazid resistant (Hr-), rifampicin resistant (RR-), multidrug-resistant (MDR-), extensive drug resistant (XDR-), and extreme drug resistant (XXDR-) TB [13, 14]. In 2017, there were an estimated
558,000 new cases of MDR/RR-TB but only $29 \%$ were reported. Low MDR/RR-TB detection rates together with lower rates of treatment success $(55 \%)$, and importantly, mismanaged TB treatment, play a key role in DR-TB emergence [1]. Recent TB modeling studies suggest that the contribution of primary DR-TB is higher than previously thought when compared to secondary or acquired resistance, and that fitness, e.g. ability to trasmit, might be similar between DRTB and drug susceptible Mycobacterium tuberculosis (M.tb) strains $[15,16]$. Moreover, implementation of molecular diagnostic tests for DR-TB is challenging in resource-constrained settings due to high costs, need for laboratory infrastructure and mainteinance, and low availability of trained/specialized personnel $[17,18]$. Although the End TB strategy recommends drug susceptibility testing (DST) in all TB cases, routine access to molecular or phenotypic DST in high TB burden areas remains limited [19]. Current evidences suggest that DR-TB could be uncontrolable without applying effective measures, such as the widespread introduction of point-ofcare (POC) DR-TB diagnosis testing methods, affordable second-line drugs, treatment of latent MDR-TB, and active monitoring of drug susceptible- and DR-TB cases in highrisk groups and crowded settings [20].

Second, the impact of HIV and other TB comorbidities has undermined TB control and prevention strategies for the past three decades. The TB/HIV syndemic accounts for increased morbidity and hidden TB transmission with its devastating effects mainly in Asia and Sub-Saharan Africa [21]. TB is the leading cause of death among people living with HIV (PLWH); in 2018, there were 251,000 deaths due to HIVassociated TB, and $85 \%$ of them occurred in Africa. In addition, TB diagnosis in PLWH is a major challenge for prevention and control strategies, as almost half of TB/HIV cases do not get proper care [22]. In this context, effective TB/HIV collaborative programs and activities are a cost-effective strategy to improve both TB and HIV treatment outcomes [23, 24].

The third major driver of TB morbidity and/or mortality is an increased life expectancy that has magnified the cooccurence of non-communicable diseases (NCDs) and their shared risk factors, including indoor pollution, smoking, alcohol and drug abuse, diabetes and malnutrition, among others. For example, diabetes mellitus triples the risk of TB development, is associated with DR-TB, and constitutes a risk factor for poor TB treatment outcomes, including death $[25,26]$. Thus, the recommendation for a coordinated and joint service delivery model integrating TB and NCDs (Fig. 1) [27].

\section{Synergy Between the SDGs and the End TB Strategy Scenarios}

In 2015, the WHO End TB strategy was developed in parallel with the SDGs, establishing a new TB control and prevention era [28]. The post-2015 era of the SDGs, created by the United 
Fig. 1 TB synergies with potential drivers for TB expansion under known TB social determinants

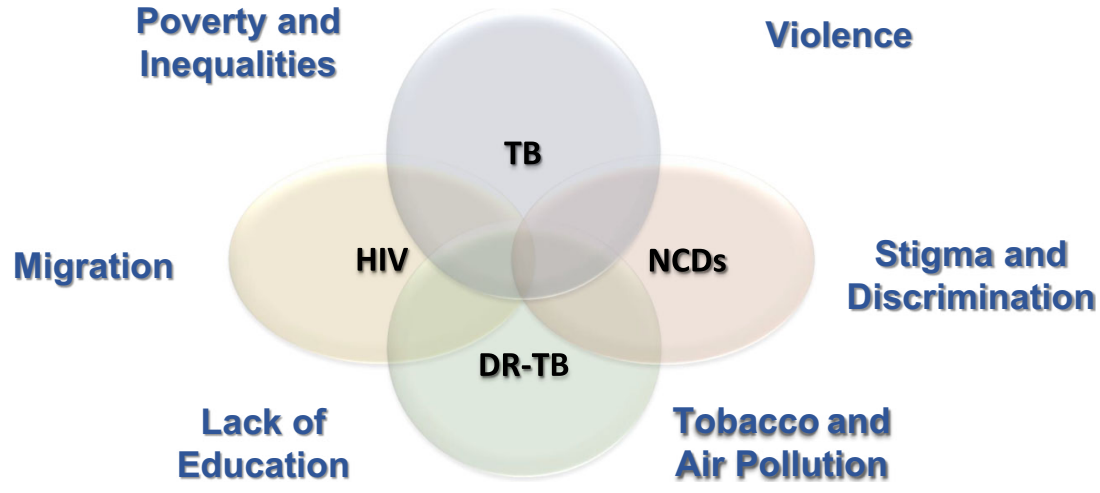

Nations (UN) to address the global challenges faced worldwide "in order to achieve a more sustainable life", has committed world leaders to "end poverty, ensuring healthy lifes and people's well-being while protecting the enviroment by 2030". Specifically, the SDG's 3.3 goal aims to "End the epidemics of AIDS, TB, malaria and neglected tropical diseases by 2030" and SDG's 3.8 goal aims to "achieve universal health coverage, including financial risk protection, access to quality essential health-care services and access to safe, effective, quality and affordable essential medicines and vaccines for all' [10]. These health targets are deeply interconnected with goals to improve sustainability, education, food security, and planetary and global health. Thus, the overlap between global TB prevention and control efforts and global sustainable development is well captured in the SDGs, which effectively addresses three major TB structural determinants, such as poverty, malnourishment and poor hygiene conditions (Table 1) [29].

The End TB strategy is built on previous achievements from past global TB programs, especifically, the direct observed therapy short course strategy of 1994 [30], and the Stop TB strategy of 2006 [31]. The End TB strategy aims to end the global TB epidemic by 2035 and is based on 3 pillars and 4 underlying principles for its implementation. There are three main indicators: Reduction in TB deaths and incidence when compared to the 2015 baseline, and reduction in the percentage of TB patients and their household members who experience catastrophic costs due to TB. Monitoring and evaluating these 3 indicators, and their associated milestones and targets, are set up for two phases, 2016-2025 and 2026-2035, respectively.

Despite outstanding achievements in science and technological innovations in global public health outcomes since World War II [32], the growing disparities in health and wealth among countries make the current world situation more inequitable than it was prior to World War I [33]. Major advances in science and global health in the past decades have not correlated with the reduction of social inequalities and poverty, which are major structural determinants of $\mathrm{TB}$ and infectious diseases worldwide [34, 35]. There is increasing evidence that the implementation of the End TB strategy alongside the SDGs may require a change in the interaction between health financing and healhcare [36], where current profit models of investment should be evaluated for transparency and effectiveness, and current oriented market and private health governance should shift to a more ecological and sustainable health-for-all model. Specifically, there are major concerns that the current model of global governance, which is based on neoliberal and capitalist values, while attempting to improve economic, social, and public health-related outcomes, has in fact accelerated biosphere degradation and human social inequalities [37]. Thus, the current implementation of SDGs through a global public health perspective [38] confronts its own roots, which are defined by capitalism structural pathogenesis [39], neocolonialism [40, 41], philanthrocapitalism [42], profit-driven commercialization of biomedical sciences [43], and the global health aid allocation status quo [44].

A new understanding of global health is needed to address global public health issues based on a world rooted in social justice $[45,46]$. Although improving diagnostics and vaccines are critical for the management of TB, a world free of TB will not be possible if social determinants of TB disease are not addressed in addition to technology advances, including a healthcare system consolidation with universal health coverage, ending poverty via social and financial protection, and ensuring nutritious food [47].

\section{End TB Strategy Pillar 1 Key Component "A": Early Diagnosis of TB Including Universal DST, and Systematic Screening of Contacts and High Risk Groups}

The first pillar to achieve the goal set by the End TB Strategy of reducing the TB incidence rate $(90 \%)$ and the number of TB deaths $(95 \%)$ by the year 2035 , is the develoment of an integrated, patient-centered TB care and prevention program that can "bring together critical interventions to ensure that all people with TB have equitable access to high-quality diagnosis, treatment, care and prevention, without facing 
Table 1 Interconnections between SDGs and the End TB strategy

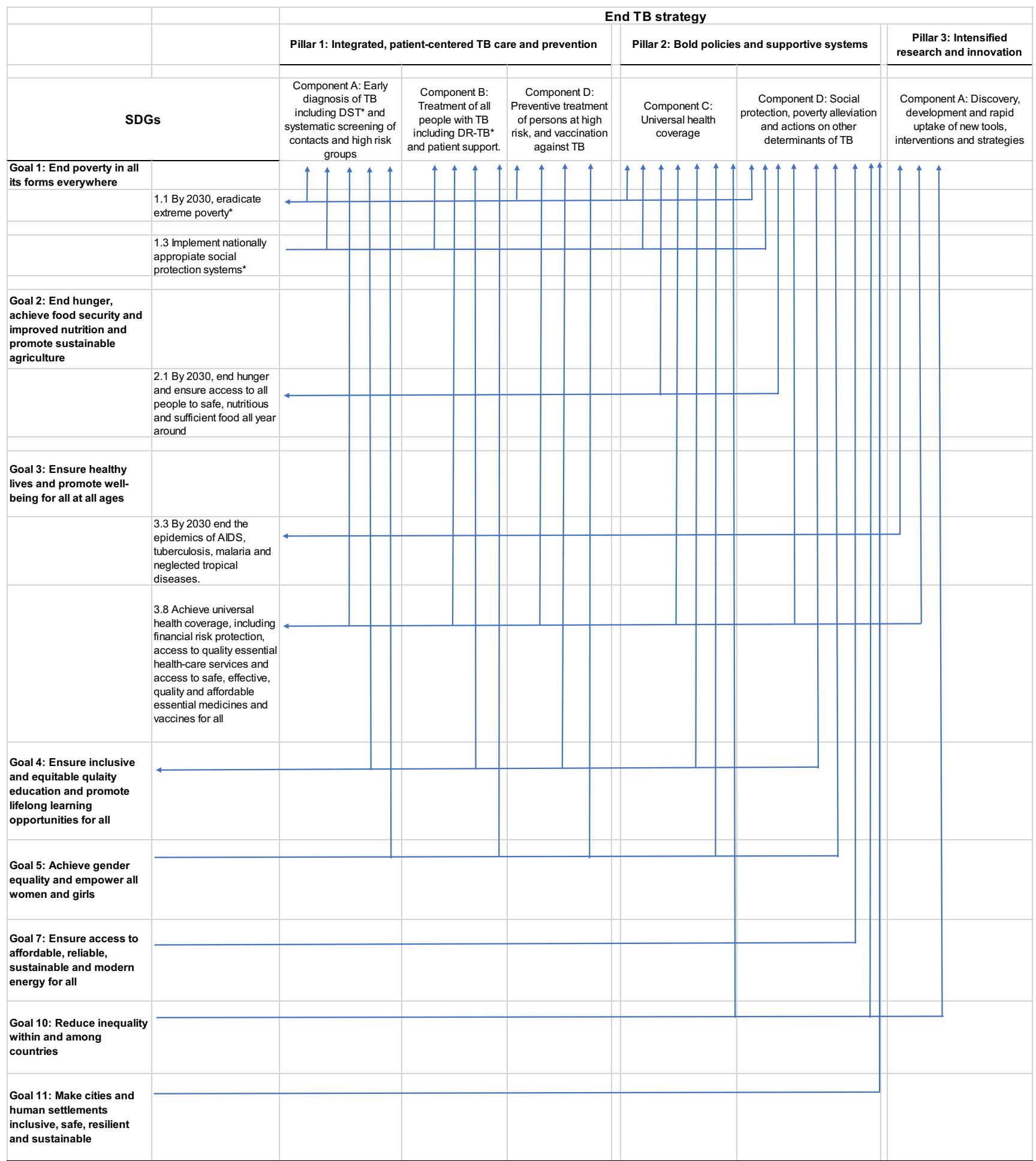

*Unidirectional and bidirectional arrows represent directions of effect

catastrophic expenditure or social repercussion" [48]. Key aims of this pillar consist of an early TB diagnosis, including systematic DST and routine screening of high-risk groups, affordable treatment for all TB patients (including those with DR-TB), the clinical management of TB comorbidities such as HIV, and preventive treatment and TB vaccination for those individuals at high risk of developing active TB. In this regard, the 2014 WHO and the Foundation for Innovative New Diagnostics (FIND) meeting report identified four major target product profiles (TPPs), defining the targets and 
specifications that new diagnostic TB tests should meet [49]: (1) a POC non-sputum test capable of detecting all forms of TB (biomarker test); (2) a simple, low-cost POC test performed in clinical/rural settings (e.g. health post) to screen and identify those who need further TB testing (triage test) [49]; (3) a POC sputum test to detect pulmonary TB to replace the widely used smear microscopy (the smear-replacement test); and (4) a rapid and efficient DST that can identify those in need of first-line drug treatment (a rapid DST test). In summary, the future of early TB diagnosis needs affordable and high-sensitivity point-of-care (POC) tests able to diagnose pulmonary and extrapulmonary TB in adults, children, and PLWH.

Several TB diagnostic tests and technologies have been developed over these past few years and summarized in Table 2. Until recently, conventional TB diagnostics have strongly relied on medical history, tuberculin skin test, chest $\mathrm{X}$-rays, microbiological culture, and acid fast staining/smear microscopy. Novel culture-based approaches have been developed to reduce time to positivity and simultaneously screen for drug susceptibility during culture, meeting the need for a rapid DST test (one of the four TPPs identified by the WHO/FIND). These recent developments include the fully automated liquid-based Mycobacteria Growth Indicator Tube (MGIT) [58], and the color plate agar-based culture test $\left[1^{\text {st }}\right.$ Generation $(1 \mathrm{G})$ TB-CX], among others [59]. Although commercial liquid culture-based DST platforms such as BD BACTEC MGIT can provide reliable results within a few days, liquid culture is prone to contamination and requires extensive laboratory infraestructure, specialized personnel, instrument calibration and maintenance, specialized reagents, etc., limiting wide implementation in low-income settings. In contrast, the $1 \mathrm{G}$ TB-CX test is based on the rapid, simple and inexpensive thin-layer agar method, and includes DST testing using a four quadrant agar plate, allowing for the early detection of MDR and pre-XDR strains (average of 13 days when compared to the 50 days required for a standard DST), with a $94 \%$ sensitivity $[59,60]$. Despite a limited number of

Table 2 Advantages and limitations of some of the newest TB diagnostic strategies

\begin{tabular}{|c|c|c|c|c|}
\hline TB diagnostic strategy ${ }^{a}$ & $\begin{array}{l}\text { Sample } \\
\text { type }\end{array}$ & Advantages & Limitations & References \\
\hline $\begin{array}{l}\text { Loop-mediated isothermal } \\
\text { amplification or LAMP } \\
\text { (NAAT) }\end{array}$ & Sputum & $\begin{array}{l}\text { - No need for a thermocycler } \\
\text { - High amplification efficiency } \\
\text { - High sensitivity and specificity } \\
\text { - Low cost; commercial kits available } \\
\text { - Easy visualization of results } \\
\text { - Simple and rapid, potential POC test }\end{array}$ & $\begin{array}{l}\text { - Needs extraction of nucleic acids } \\
\text { - Specificity relies on good primer design } \\
\text { - In some cases, enrichment methods before PCR } \\
\text { amplification are needed }\end{array}$ & $\begin{array}{l}\text { Sahoo et al. [50]; } \\
\text { WHO et al. [51] }\end{array}$ \\
\hline $\begin{array}{l}\text { Lateral-flow urine LAM } \\
\text { test (LF-LAM) and } \\
\text { related }^{\text {b }}\end{array}$ & Urine & $\begin{array}{l}\text { - Appropriate when sputum sample is } \\
\text { difficult to obtain or in } \\
\text { extrapulmonary TB (such as in } \\
\text { PLWH) } \\
\text { - Fast, POC test } \\
\text { - Needs very little amount of sample }\end{array}$ & $\begin{array}{l}\text { - Low sensitivity } \\
\text { - Requires confirmation by other methods } \\
\text { - Needs previous clinical suspicion of TB to } \\
\text { perform the test } \\
\text { - Only detected in people with active TB }\end{array}$ & $\begin{array}{l}\text { Singhroy et al. [52]; } \\
\text { WHO et al. [53] }\end{array}$ \\
\hline $\begin{array}{l}\text { Host-response-based } \\
\text { diagnostics: } \\
\text { transcriptomics and/or } \\
\text { proteomics signature }\end{array}$ & Blood & $\begin{array}{l}\text { - Prognostic value: prevent TB } \\
\text { disease progression, allowing for } \\
\text { targeted treatment and/or case } \\
\text { investigation } \\
\text { - Fast } \\
\text { - Potential to be used as POC test }\end{array}$ & $\begin{array}{l}\text { - Host responses influenced by other TB } \\
\text { co-morbidities and host genetic background: } \\
\text { one transcriptomic/proteomic signature does } \\
\text { not fit all } \\
\text { - Needs standardization } \\
\text { - Sensitivity and specificity differ among cohorts } \\
\text { and between different proposed signatures }\end{array}$ & $\begin{array}{l}\text { Warsinske et al. [54]; } \\
\text { Penn-Nicholson } \\
\text { et al. [55••] }\end{array}$ \\
\hline $\begin{array}{l}\text { Whole-genome } \\
\text { sequencing (WGS) }\end{array}$ & Sputum & $\begin{array}{l}\text { - Whole bacterial genome information } \\
\text { - Highly accurate } \\
\text { - No need for culture, advances in the } \\
\text { detection of M.tb directly from } \\
\text { clinical samples } \\
\text { - Short turnaround time } \\
\text { - Multiple applications: diagnostics, } \\
\text { epidemiology, DR profiling, M.tb } \\
\text { evolution } \\
\text { - Identification of new DR mutations } \\
\text { - Identification of mixed infections } \\
\text { - Portable platforms (e.g. MinION) }\end{array}$ & $\begin{array}{l}\text { - Need for high sequencing depth to detect } \\
\text { mutations (increased cost) } \\
\text { - Difficult to implement in low income countries } \\
\text { with few resources } \\
\text { - Need of well-defined genotypic-phenotypic } \\
\text { associations } \\
\text { - Complex data analysis: requires bioinformatics } \\
\text { expertise }\end{array}$ & $\begin{array}{l}\text { Soundararajan et al. } \\
\text { [56]; Cohen et al. } \\
\text { [57] }\end{array}$ \\
\hline
\end{tabular}

${ }^{\text {a }}$ There are other strategies and related tests such as the Lionex test and the new FujiLAM test not mentioned in the table but included in the main text

${ }^{\mathrm{b}}$ Endorsed by the World Health Organization (WHO) 
studies in very specific settings, the $1 \mathrm{G}$ TB-CX test, at the cost of US\$1.35, has the potential to be a good alternative method for the fast and low-cost diagnosis of DS and MDR TB in countries with poor health infraestructure [59]. A drawback for the $1 \mathrm{G}$ TB-CX is that only classifies the extent of drug resistance (susceptible, MDR, and pre-XDR TB), but it can only be used to provide schematic of treatment for drug susceptible patients. Thus, a $2 \mathrm{G}$ TB-CX test has been developed (US\$8.5) and is currently being tested in the lab setting, with the advantage of being able to test for up to 11 TB drugs, including bedaquiline and delamanid, both currentlly being used to treat DR-TB [61].

Despite these latest advancements, culture-based methods strongly rely on obtaining a good quality sputum sample and enriching for M.tb to increase bacterial load above the detection limit, which might prove difficult in PLWH and children $[62,63]$. Thus, new POC developments in TB diagnostics are moving towards rapid molecular tests and/or indirect methods that look into the specific host responses against TB infection (e.g. biomarker test), which can serve as rapid and inexpensive POC tests to detect pulmonary and extrapulmonary TB in clinical settings, fulfilling the needs determined by the WHO/FIND TTPs [49]. Nucleic acid amplification tests, such as Xpert MTB/RIF [64] and loop-mediated isothermal amplification (TB-LAMP) [65], have been endorsed by the WHO for the diagnosis of pulmonary $\mathrm{TB}$, and are currently playing a critical role in TB diagnostics [66].

Non-sputum-based biomarker assays are also being developed as alternative low-cost POC tests to rapidly identify those that require further TB testing (triage test) and to detect all forms of TB. In this regard, in 2015, the WHO first recommended the broaden use of lateral-flow urine mycobacterial cell wall component lipoarabinomannan (LAM) detection for the screening of active TB in PLWH (both pulmonary and extrapulmonary) [53]. Thus, the Alere Determine TB LAMAg test (Abbott, Chicago, IL, USA, US\$3.5/cost) is based on polyclonal antibodies of unknown specificity recognizing the mycobacterial LAM antigen in urine, and has shown a pooled sensitivity of $53 \%$ in PLWH (with $<100 \mathrm{CD} 4 \mathrm{~T}$ cells $/ \mathrm{mm}^{3}$ ) with TB clinical symptoms [67]. Recent efforts have been made to improve the efficacy and sensitivity of this test, including a simple $\alpha$-mannosidase sample pre-treatment (for $15 \mathrm{~min}$ at room temperature) that structurally modifies LAM in urine, increasing the affinity of the Alere Detemine LAMAg test polyclonal antibodies and consequently, the test detection levels by 10 -fold [68], adding only a US $\$ 0.50$ cost to the Alere Determine LAM-Ag test. A new LAM test using known antibodies (FujiLAM) has also been reported with an increase in sensitivity of $28.1 \%$ over the Alere Determine LAM-Ag test, while maintaining specificity [69••]. Another new LAM test is the Lionex-test. This is a serological assay detecting $\operatorname{IgA} / \operatorname{IgG} / \operatorname{IgM}$ antibodies against LAM and a mixture of recombinant $M . t b$ antigens in whole blood, serum, plasma and milk (the latter for Bovine TB diagnostics). The cost of this test is US\$6.25, and results are obtained in 20 min with $85-90 \%$ sensitivity and $97 \%$ specificity [70]. Further studies are needed to increase diagnostic sensitivity of LAM tests in PLWH, and expand its use as a POC test to both non-HIV infected and PLWH at high risk of TB morbidity and mortality.

Indirect blood PCR-based biomarker tests looking at the host immune response to TB infection are being developed and validated as diagnostic tools, targeting all forms of TB and patient populations [71]. The main advantage of these assays compared to other tests is their prognostic value, with the potential to predict individuals with high-risk of TB progression or even recent exposure, in order to determine those in need of treatment and/or monitor prolonged therapy. In this regard, a systematic comparison study of 16 host-derived gene expression signatures [54] found that 7 out of 16 signatures predicted progression from latent to active TB disease 6 months prior to sputum conversion (e.g. incipient TB), and 2 of the proposed gene profiles satisfied the WHO criteria for a non-sputum triage test across heterogeneous datasets (achieving a $74 \%$ specificity at $90 \%$ sensitivity), and indicating that some host-response-based diagnostics could be generalizable across diverse patient populations and thus, considered for clinical implementation [55••]. Moreover, RISK-6 is also described as a robust blood 6-gene transcriptomic signature, not significantly affected by underlying HIV-infection, showing promising potential as a universal biomarker test [72]. A new study also suggests that a proteomic signature may accurately predict TB disease progression, relapse or re-infection, although more work is needed to increase the performance of such tests before these can be widely implemented [73].

In recent years, whole-genome sequencing (WGS)-based diagnostics are gaining popularity in the TB field [74]. Since the first M.tb genome was sequenced in $1998[75 \cdot]\left(\mathrm{H}_{37} \mathrm{R}_{\mathrm{v}}\right.$ strain) next generation sequencing technologies have greatly improved, and are now able to provide rapid and accurate sequencing of whole bacterial genomes in a short timeframe of hours to days at a relatively reduced cost. Some of the advantages that WGS-based strategies have when compared to other TB diagnostic methods, are the short turnaround time for results, as well as the vast amount of information provided, which can be translated into multiple applications: species/ strain identification and characterization, to identify drug resistance and generate susceptibility profiles to inform treatment, to identify mixed infections, and/or to conduct outbreak investigations/epidemilogy. The depth of information provided in a single WGS test has the potential to improve the speed and accuracy of MDR-TB diagnosis at or near the point-ofcare and be simultaneously used as an epidemiological tool, revolutionizing the TB field [76].

Indeed, as most of the M.tb complex species and strains share more than $99 \%$ nucleotide similarity, WGS has already 
played a critical role in deciphering key genomic variance thanks to its nucleotide-level resolution, allowing not only strain identification but the identification of small genetic variances that can cause clinically relevant phenotypic differences. This is the case of mutations that confer drug resistance, largely associated to single nucleotide polymorphims. Several studies have demonstrated the potential value of WGS in predicting drug resistance phenotypes from the mycobacterial genome as a surveillance and screening tool which would serve as rapid DST test at POC settings and help taking informed decisions about extended TB treatments [57]. However, further research is needed in this area as the genetic basis for drug resistance is not fully understood yet and some unknown DR-conferring mutations could be missed if solely looking at the genome [77].

Perphaps the greatest benefit of WGS is the potential ability to detect and sequence M.tb directly from clinical samples without the need for culture, which would be transformative and greatly improve TB management, serving as a fast POC test in clinical settings [78, 79]. Although promising, it also represents the biggest challenge, as direct patient samples contain variable amounts of M.tb mixed with other microorganisms and human DNA, where M.tb usually represents less than $1 \%$ of the total extracted DNA. Several advances have been done to obtain sufficient proportion of pathogen DNA in order to capture the pathogen genome at sufficient coverage, including targeted capturing of M.tb cells or DNA (mycobacterial enrichment), or host DNA depletion strategies [80].

Due to higher costs compared to traditional microbiological techniques, and required computing and bioinformatics capabilities, implementation of WGS in resource-constraint settings is still a challenge nowadays. Although WGS technologies are advanced enough to inform clinical decisions and have rapidly evolved from research to diagnostics/ epidemiological tools, the development of standardized and validated protocols and international guidelines is critical in order to translate sequencing data into actionable information that can be applicable for TB diagnostics and public health surveillance worlwide [81]. Nevertheless, WGS strategies, due to the numerous advantages compared to traditional TB tests and the power to combine numerous applications in a single test, holds the potential to be the future of TB diagnostics, if adequate resources for TB care and prevention policies can be implemented worldwide.

\section{End TB Strategy Pillar 1 Key Component "D": Preventive Treatment of Persons at High Risk, and Vaccination Against TB}

In-depth evaluation of the M. bovis Bacille Calmette-Guerin (BCG) against TB disease has been recently reviewed elsewhere by us and others $[82,83]$. Despite more than 100 years of vaccine research in the TB field, there is still a lack of an effective vaccine against TB [84]. The BCG vaccine provides protection in infants and adolescents against lethal forms of TB such as meningeal and miliary TB, but it is not considered effective in preventing pulmonary TB in adults due to previous infection with M.tb, and sensitization with enviromental mycobacteria, among other factors [83]. However, recent sudies have provided proof-of-concept that efficacy of TB vaccination is achievable. A study by Nemes et al., showed that revaccination with $\mathrm{BCG}$ reduced quantiferon conversion in South African children by $45.4 \%$ [85*0]. Further, the subunit vaccine $\mathrm{M} 72 / \mathrm{AS} 01_{\mathrm{E}}$ provided a $49.7 \%$ efficacy in preventing pulmonary TB in adults 36 months postvaccination $[86 \bullet \bullet$.

Currently, the TB vaccination strategy relies on three main approaches: prophylactic vaccination, post-exposure vaccination, and therapeutic vaccines [87]. In addition, WHO launched a document with prefered vaccine characteristics which is guiding research and industry towards a future TB vaccine; these characteristics are measured under three different endpoints: (i) Prevention of pulmonary TB disease (PoD), (ii) Prevention of recurrent TB disease due to relapse or reinfection in already infected people (PoR), and (iii) Prevention of M.tb infection in uninfected people (PoI) [87]. In this regard, modeling studies suggest that a major impact on TB vaccination would be achieved by a vaccine, assuming a $60 \%$ vaccine efficacy with a 10 years duration of protection, targeting adolescents and adults in low income countries under the PoD endpoint $[88,89]$.

There are currently several promising TB vaccines under phase 2b-3 clinical trials: VPM 1002 and its derivatives, the subunit vaccine M72/AS01E to boost BCG, the recombinant protein vaccine $\mathrm{H} 56: \mathrm{IC} 31$, and $\mathrm{BCG}$ revaccination strategies reviewed elsewhere [90]. However, there are two important caveats in TB vaccine development approaches: (1) the narrow focus in generating $\mathrm{CD} 4^{+} \mathrm{Th} 1$ cells; and (2) the lack of validated immune correlates of protection [91]. Apart from $\mathrm{CD}^{+} \mathrm{T}$ cells, $\mathrm{B}$ cells, and unconventional $\mathrm{T}$ cells may have an important role in generating immune protection against TB. Exploring the ability of trained immunity [(innate immune mechanisms driving a degree of resistance to reinfection [92])] to control TB in the lung parenchyma and pulmonary mucosa is critical $[93,94]$. Antibodies, apart of physically blocking M.tb, might enhance macrophage phagocytic activity and play a crucial role in stimulating cytokine secretion and recruitment of natural killer cells, monocytes and phagocytes [95-97]. In this regard, an IgG monoclonal antibody against M.tb $\mathrm{H}_{37} \mathrm{R}_{\mathrm{v}}$ strain LAM in a mice model of M.tb infection showed a dose dependent M.tb burden reduction in spleen and lungs and increased long-term survival of mice [98].

TB vaccine development would be improved by widening TB vaccine research through expanding our current knowledge of immune correlatives of protection conferred by Human Leukocyte Antigen (HLA) type I and II restricted antigen 
presentation to unconventional $\mathrm{T}$ cells. In this regard, donor unrestricted T-cells (DURST) are activated by M.tb antigens presented by dendritic cells and macrophages through restriction molecule ligands such as CD1 molecules [99], major histocompatibility complex class-I related protein 1 (MR1) [100], and HLA-E [101, 102]. Exploring DURST for TB vaccines may contribute to protective immunity, and offer a complementary path to explore alternatives to classical T-cell immunity, although the duration and stability of such protective responses needs further investigation [103].

Other lines of research to improve TB vaccination are directed towards addressing mucosal immunization and alternative routes of $\mathrm{TB}$ vaccination. In this context, inhalable TB vaccines offer the potential to mimic the natural route of $M . t b$ infection and provide durable mucosal immune responses which may be critical for M.tb control [104, 105]. In this regard, intranasal administration of whole cell inactivated MTBVAC HK vaccine in mice, improved the protective efficacy of mice previously vaccinated with subcutanous BCG, by triggering mucosal secretory immunoglobulins [106]. In addition, pre-exposure of BCG with human lung mucosa followed by subcutaneous vaccination increased BCG protection against M.tb infection, indicating that early events happening in the alveolar space may contribute to BCG efficacy [107•]. Indeed, optimizing the design of polymeric nanocapsules for intranasal vaccination have the potential to increase immune reponses against M.tb infection [108]. Mucosal delivery and BCG delipidation strategies are also currently being investigated [109]. In this regard, a selective chemical treatment of BCG to remove inflammatory lipids from the BCG bacterial cell surface increased protection, relative to conventional BCG, against M.tb challenge in mice after intranasal vaccination [107•].

Additionally, the fields of nanovaccines and mRNA vaccination have emerged as powerful tools to improve TB vaccine efficay and delivery. Nanovaccines refer to the science of vaccination based on nanoparticles, which include several types of materials within the range of 10 to $1000 \mathrm{~nm}$ such as liposomes, dendrimers, micelles, carbon nanotubes, and metallic NPs that can be used for vaccine delivery. Several advantages of nanovaccines vs. traditional vaccines are improved stability in blood, no need to maintain the cold chain, and the ability to create active targeting to specific cells or tissues (e.g. using monoclonal antibody coated nanoparticles) [110]. Indeed, a study involving a fusion protein of M.tb ESAT-6 (6 kDa early secretory antigenic target) and CFP-10 (10 kDa culture filtrate protein) absorbed into a polymeric nanocapsule using a Toll-like receptor-7 (TLR-7) agonist as a coadjuvant, showed mucosal immunization in mice after intranasal challenge [108]. Other strategies used with other pathogens have the potential to be extrapolated for immunization against TB.
For example, a polyanhydride-based nanovaccine encapsulating mycobacterial antigens of $M$. paratuberculosis showed development of protective immnune responses against Johne's disease in a mice model [111].

Another potential strategy is mRNA vaccination, which is an emerging tool with the potential to replace traditional vaccinology approaches and is currently on the front edge of vaccine development strategies for the Severe Acute Respiratory Syndrome Coronavirus 2 (SARS-CoV-2) infection [112]. Early studies in the 90s showed that direct DNA and RNA injection in animal models led to in vivo expression of proteins encoded by the injected nucleic acids. Since then, increased mRNA stability, improved delivery, and protein expression, have fuelled this dynamic research field into recent RNA vaccine delivery appoaches such as selfamplifying RNA vaccines [113]. Indeed, a single dose of naked mRNA vaccine with Hsp65 protein from $M$. leprae delivered intranasally in mice showed specific correlates of immune protection through IL-10 and TNF production [114]. An investigational subunit vaccine (ID93 in phase 2b clinical trials) agaisnt TB has also been recently adapted into a self replicating mRNA molecule formulated into a nanostructured lipid carrier, with the finality to assess the magnitude of the immune response generated compared to its protein based formulation [115].

Finally, controlled human infection models (CHIMs) are used in infectious disease vaccinology studies for pathogens such as malaria, influenza and dengue virus, and these may also be useful for TB vaccine development. Even though M.tb cannot be used to challenge humans, alternative CHIMs using BCG might provide a better understanding on host immunopathogenesis responses and can be applied to complement preclinical animal studies for vaccine selection and develoment [116]. In this regard, intradermal BCG challenge studies, (as a surrogate for human M.tb challenge), in healthy individuals have shown that those previously BCGvaccinated had some degree of protective immunity to BCG [117•]. This model has been optimized showing that the CHIM BCG challenge dose affects the sensitivity of this model [118]. Moreover, bronchoschopic instillation of live BCG and M.tb purified protein derivative (PPD) in a CHIM study in South Africa with uninfected participants allowed to assess the feasibility and safety of this model providing the foundation for future advances in TB immunopathogenesis, biosignatures of TB risk and better models to evaluate vaccine efficacy [119].

The current COVID-19 pandemic has brought attention to the potential use of $\mathrm{BCG}$ in protecting from SARS-CoV-2 infection and COVID-19 disease due to $\mathrm{BCG}$ protection against viral pathogens through trained immunity, including heterologus lymphocyte activation 
[120], innate immune memory, and enhanced cytokine production [120, 121]. Nowadays, the effectiveness of BCG against COVID-19 is unknown and results from ongoing randomised control trials will bring clarity to this key question [122].

\section{Concluding Remarks}

The End TB strategy depends on current developments in POC TB diagnostics to achieve enhanced sensitivity and specificity and a timely and expanded use. As we target a TB elimination phase, we envision a full array of complementary TB screening assays and algorithms to be implemented depending on the type of health care setting [9]. Conversely, recent techonological advances and achievements provide optimism towards the goal of developing effective TB vaccines, even though, one vaccine approach might not fit to all, and different approaches with different types of vaccines may be a feasible solution to achieve a sustainable mass scale vaccination. A critical issue will be how to engage multisectorial partnerships, from national to districtal governancies, in order to strenghten human resources to deliver and properly implement TB vaccines and diagnostics strategies in an affordable manner with no costs for TB patients, and little for health systems, on the way to achieve social protection and universal health coverage.

In this context, the achievement of the SDGs may not be possible under the current models of governance. While SDGs recognize that contribution of structural factors such as poverty, malnutrition, and lack of access to education are critical to health outcomes, they stop short of addressing policies and trade agreements that have contributed to widening economic and social inequities inter- and intra-nationally. To truly close this gap, SDGs may need to address issues such as the neocolonial monopolization of south equatorial natural resources by the North for their own profit; enforcement of intellectual property laws not only to protect financial interests of inventors/investors, but also allowing competitive costs to avoid limiting access to life-saving technologies to the general public; and implement trade and advertising policies that place downward pressure on the prices of fast food, alcohol, and tobacco globally, that precipitate the double burden of malnutrition and explosion of non-communicable diseases in lowincome populations. Though the development of improved diagnostics and an effective vaccine are critical in the fight to eradicate TB, it is also important to understand the political and economic frameworks under which social inequalities, and thus health inequalities, are allowed to thrive.

Abbreviations CHIMs, Controlled human infection models; COVID19, Coronavirus disease 2019; DURST, Donor unrestricted T-cells; DR-
$T B$, Drug-resistant TB; $D S T$, Drug susceptibility testing; $X D R-T B$, Extensive drug resistant; $T B(X X D R-T B)$, Extreme drug resistant; $F I N D$, Foundation for Innovative New Diagnostics; HLA, Human Leukocyte Antigen; $H r-T B$, Isoniazid resistant TB; $M D G s$, Millennium Development Goals; $M D R-T B$, Multidrug-resistant TB; MGIT, Mycobacteria Growth Indicator Tube; $B C G$, Mycobacterium bovis Bacille Calmette-Guerin; M.tb, Mycobacterium tuberculosis; NCDs, Non-communicable diseases; PLWH, People living with HIV; POC, Point-of-care; PoI, Prevention of M.tb infection in uninfected people; $P o D$, Prevention of pulmonary TB disease; $P o R$, Prevention of recurrent TB disease due to relapse or reinfection in already infected people; $R R$ $T B$, Rifampicin resistant TB; SARS-CoV-2, severe acute respiratory syndrome coronavirus 2; $S D G s$, Sustainable development goals; TPPs, Target product profiles; $T B$, Tuberculosis; $U N$, United Nations; WGS, Whole-genome sequencing; $W H O$, World Health Organization

Acknowledgements The authors dedicate this review to the people suffering of TB disease worldwide.

Funding This study was supported by the Ruth Chapman Cowles and Andrew G. Cowles Memorial Trust to JIG, and by the Robert J. Kleberg, Jr and Helen C. Kleberg Foundation to JBT.

\section{Declarations}

Human and Animal Rights and Informed Consent This article does not contain any studies with human or animal subjects performed by any of the authors.

Conflict of Interest Juan Ignacio Garcia, Anna Allue-Guardia, Radhika P. Tampi, Blanca I. Restrepo, and Jordi B. Torrelles declare that they have no conflict of interest.

\section{References}

Papers of particular interest, published recently, have been highlighted as:

- Of importance

• Of major importance

1. World Health Organization (WHO). Global Tuberculosis Report 2019: World Health Organization; 2019. [cited 2020 Aug 26]. Available from: https://www.who.int/tb/global-report-2019

2. Kyu HH, Maddison ER, Henry NJ, Mumford JE, Barber R, Shields $\mathrm{C}$, et al. The global burden of tuberculosis: results from the Global Burden of Disease Study 2015. Lancet Infect Dis. 2018;18(3):261-84 [cited 2018 Oct 5]. Available from: http:// www.ncbi.nlm.nih.gov/pubmed/29223583.

3. Tanimura T, Jaramillo E, Weil D, Raviglione M, Lönnroth K. Financial burden for tuberculosis patients in low- and middleincome countries: a systematic review. Eur Respir J. 2014;43: 1763-75 [cited 2020 Jul 10]. Available from: https://pubmed. ncbi.nlm.nih.gov/24525439/.

4. Ukwaja KN, Modebe O, Igwenyi C, Alobu I. The economic burden of tuberculosis care for patients and households in Africa: a systematic review. Int J Tuberc Lung Dis. 2012;16:733-9.

5. Walcott RL, Ingels JB, Corso PS, Zalwango S, Whalen CC, Sekandi JN. There's no such thing as a free TB diagnosis: catastrophic TB costs in urban Uganda. Glob Public Health. 2020;15(6):877-88. 
6. Togun T, Kampmann B, Stoker NG, Lipman M. Anticipating the impact of the COVID-19 pandemic on TB patients and TB control programmes. Ann Clin Microbiol Antimicrob. 2020;19:1-6. Available from. https://doi.org/10.1186/s12941-020-00363-1.

7. Schneider EC. Covid's color line - infectious disease, inequity, and racial justice. N Engl J Med. 2020;383(5):405-8.

8. Stop TB partnership. The potential impact of the covid-19 response on tuberculosis in high-burden countries: a modelling analysis. Dev by Stop TB Partnersh Collab with Imp Coll Avenir Heal Johns Hopkins Univ USAID; 2020. p. 1-7. [cited 2020 Sep 10]. Available from: http://www.stoptb.org/assets/documents/news/ ModelingReport_1May2020_FINAL.pdf

9. World Health Organization (WHO). The End TB strategy, vol. 91; 2012. Available from: https://www.who.int/tb/End_TB_brochure. pdf?ua=1

10. United Nations. The Sustainable Development Goals. 2015. [cited 2020 Aug 22]. Available from: https://sdgs.un.org/goals

11. United Nations. The Millenium Development Goals Report 2015: United Nations; 2015. [cited 2020 Aug 22]. Available from: https://www.un.org/millenniumgoals/2015_MDG_Report/pdf/ MDG2015rev(July1).pdf

12. Becerra-Posada F. Health in all polices: a strategy to support the Sustainable Development Goals. Lancet Global Health. 2015;3: e360 Elsevier Ltd; [cited 2020 Aug 21]. Available from: www. thelancet.com/lancetgh.

13. World Health Organization. WHO consolidated guidelines on drug-resistant tuberculosis treatment. 2019 [cited 2019 Oct 29]. Available from: http://apps.who.int/bookorders.

14. World Health Organization (WHO). Meeting report of the WHO expert consultation on the definition of extensively drug-resistant tuberculosis. Geneva: World Health Organization; 2020. Available from: https://apps.who.int/iris/handle/10665/338776

15. Luciani F, Sisson SA, Jiang H, Francis AR, Tanaka MM. The epidemiological fitness cost of drug resistance in Mycobacterium tuberculosis. Proc Natl Acad Sci U S A. 2009. [cited 2020 Jun 30]. Available from;106. https://doi.org/10.1073/pnas.0902437106.

16. Cohen T, Murray M. Modeling epidemics of multidrug-resistant M. tuberculosis of heterogeneous fitness. Nat Med. 2004;10(10): 1117-21.

17. Médecins Sans Frontières. Out of Step: TB policies in 29 countries, Médecins Sans Frontières Access Campaign. 3rd ed. [cited 2020 Jun 30]. Available from: https://msfaccess.org/out-step-tbpolicies-29-countries-3rd-ed

18. Clouse K, Blevins M, Lou LM, Yotebieng M, Nguyen DT, Omondi A, et al. Low implementation of Xpert MTB/RIF among HIV/TB co-infected adults in the International epidemiologic Databases to Evaluate AIDS (IeDEA) program. PLoS One. 2017;12(2) [cited 2020 Jul 16] Available from: www.iedea.org.

19. Nathavitharana RR, Lederer P, Tierney DB, Nardell E. Treatment as prevention and other interventions to reduce transmission of multidrug-resistant tuberculosis. Int $\mathrm{J}$ Tuberc Lung Dis. 2019;23(4):396-404.

20. Dheda K, Gumbo T, Maartens G, Dooley KE, Murray M, Furin J, et al. The Lancet Respiratory Medicine Commission: 2019 update: epidemiology, pathogenesis, transmission, diagnosis, and management of multidrug-resistant and incurable tuberculosis. Lancet Respir Med. 2019;7:820-6 [cited 2020 Jul 10]. Available from: www.thelancet.com/respiratory.

21. Granich R, Gupta S. Two diseases, same person: moving toward a combined HIV and tuberculosis continuum of care. Int J STD AIDS. 2018;29(9):873-83. [cited 2018 Oct 9]. Available from. https://doi.org/10.1177/0956462418761930.

22. World Health Organization. WHO | TB and HIV and other comorbidities: WHO; 2020. [cited 2020 Aug 6]; Available from: http://www.who.int/tb/areas-of-work/tb-hiv/en/
23. Uyei J, Coetzee D, Macinko J, Guttmacher S. Integrated delivery of HIV and tuberculosis services in sub-Saharan Africa: a systematic review. Lancet Infect Dis. 2011;11(11):855-67 [cited 2018 Oct 2]. Available from: http://linkinghub.elsevier.com/retrieve/ pii/S1473309911701451.

24. Restrepo BI. Convergence of the tuberculosis and diabetes epidemics: renewal of old acquaintances. Clin Infect Dis. 2007;45(4): 436-8 [cited 2021 Mar 6]. Available from: /pmc/articles/ PMC2900315/.

25. Liu Q, Li W, Xue M, Chen Y, Du X, Wang C, et al. Diabetes mellitus and the risk of multidrug resistant tuberculosis: a metaanalysis. Sci Rep. 2017;7(1):1-7. Available from. https://doi.org/ 10.1038/s41598-017-01213-5.

26. Noubiap JJ, Nansseu JR, Nyaga UF, Nkeck JR, Endomba FT, Kaze AD, et al. Global prevalence of diabetes in active tuberculosis: a systematic review and meta-analysis of data from 2.3 million patients with tuberculosis. Lancet Glob Heal. 2019;7(4):e448-60.

27. Marais BJ, Lönnroth K, Lawn SD, Migliori GB, Mwaba P, Glaziou P, et al. Tuberculosis comorbidity with communicable and non-communicable diseases: Integrating health services and control efforts. Lancet Infect Dis. 2013;13(5):436-48.

28. Uplekar M, Raviglione M. WHO's End TB Strategy: from stopping to ending the global TB epidemic. Indian J Tuberculosis. 2015;62:196-9.

29. Rehm J, Samokhvalov AV, Neuman MG, Room R, Parry C, Lönnroth $\mathrm{K}$, et al. The association between alcohol use, alcohol use disorders and tuberculosis (TB). A systematic review. BMC Public Health. 2009;9:1-2.

30. World Health Organization. WHO Tuberculosis Programme: framework for effective tuberculosis control. Geneva: World Health Organization; 1994. Available from: https://apps.who.int/ iris/handle/10665/58717

31. Uplekar M, Stop TB Partnership, World Health Organization. The Stop TB strategy : building on and enhancing DOTS to meet the TB-related Millennium Development Goals. Geneva: World Health Organization; 2006.

32. Jamison DT, Summers LH, Alleyne G, Arrow KJ, Berkley S, Binagwaho A, et al. Global health 2035: a world converging within a generation. Lancet. 2013;382(9908):1898-955. Available from. https://doi.org/10.1016/S0140-6736(13)62105-4.

33. Benatar SR, Daar AS, Singer PA. Global health ethics: The rationale. Int Aff. 2003;79:107-38.

34. Gill S, Benatar S. Global health governance and global power: a critical commentary on the Lancet-university of Oslo commission report. Int J Heal Serv. 2016;46(2):346-65.

35. Bhutta ZA, Black RE. Global maternal, newborn, and child health — so near and yet so far. N Engl J Med. 2013;369(23):2226-35. [cited 2020 Jun 16]. Available from. https://doi.org/10.1056/ NEJMra1111853.

36. Morton S, Pencheon D, Squires N. Sustainable Development Goals (SDGs), and their implementation. Br Med Bull. 2017;124(1):81-90.

37. Labonté R. Health promotion in an age of normative equity and rampant inequality. Int J Health Policy Manag. 2016;5:675-82 Kerman University of Medical Sciences; [cited 2020 Jun 22]. Available from: http://www.ijhpm.com/article_3243.html.

38. Taylor S. Global health: meaning what? BMJ Glob Heal. 2018;3(2):e000843. Available from. https://doi.org/10.1136/ bmjgh-2018-000843.

39. Sell SK, Williams OD. Health under capitalism: a global political economy of structural pathogenesis. Rev Int Polit Econ. 2020;27(1):1-25.

40. Eichbaum QG, Adams LV, Evert J, Ho MJ, Semali IA, van Schalkwyk SC. Decolonizing Global Health Education: Rethinking Institutional Partnerships and Approaches. Acad Med. 2021;96(3): 329-35. 
41. The Lancet Global Health. Decolonising COVID-19. Lancet Glob Heal. 2020;8(5):e612. Available from. https://doi.org/10.1016/ S2214-109X(20)30134-0.

42. Reubi D. Epidemiological accountability: philanthropists, global health and the audit of saving lives. Econ Soc. 2018;47(1):83-110.

43. de Melo-Martín I. The commercialization of the biomedical sciences: (mis)understanding bias. Hist Philos Life Sci. 2019;41(3): $1-17$.

44. Olawore O, Tobian AAR, Kagaayi J, Bazaale JM, Nantume B, Kigozi G, et al. Migration and risk of HIV acquisition in Rakai, Uganda: a population-based cohort study. Lancet HIV. 2018;5(4): e181-9 [cited 2019 Oct 16]. Available from: http://www.ncbi. nlm.nih.gov/pubmed/29490875.

45. Kickbusch I. Global health governance challenges 2016 - are we ready? Int J Health Policy Manag. 2016;5:349-53 [cited 2020 Jun 22]. Kerman University of Medical Sciences; Available from: http://www.ijhpm.com/article 3171.html.

46. Horton R, Beaglehole R, Bonita R, Raeburn J, McKee M, Wall S. From public to planetary health: a manifesto. Lancet. 2014;383(9920):847. Available from. https://doi.org/10.1016/ S0140-6736(14)60409-8.

47. Lönnroth K, Raviglione M. The WHO's new end tb strategy in the post-2015 era of the sustainable development goals. Trans R Soc Trop Med Hyg. 2015;110(3):148-50.

48. World Health Organization (WHO). Implementing the End TB strategy: the essentials. World Health Organization. 2015; https://apps.who.int/iris/handle/10665/206499.

49. World Health Organization. High-priority target product profiles for new tuberculosis diagnostics: report of a consensus meeting: World health Organisation; 2014. [cited 2020 Jul 3]. Available from: www.who.int

50. Sahoo PR, Sethy K, Mohapatra S, Panda D. Loop mediated isothermal amplification: an innovative gene amplification technique for animal diseases. Vet World. 2016;9(5):465-9 [cited 2020 Aug 24]. Available from:/pmc/articles/PMC4893716/ ?report=abstract.

51. World Health Organization (WHO). The use of loop-mediated isothermal amplification (TB-LAMP) for the diagnosis of pulmonary tuberculosis, vol. 1; 2016.

52. Singhroy DN, MacLean E, Kohli M, Lessem E, Branigan D, England $\mathrm{K}$, et al. Adoption and uptake of the lateral flow urine LAM test in countries with high tuberculosis and HIV/AIDS burden: current landscape and barriers. Gates Open Res. 2020;4:24. [cited 2020 Aug 24]. Available from. https://doi.org/10.12688/ gatesopenres.13112.1.

53. World Health Organization (WHO). Lateral flow urine lipoarabinomannan assay (LF-LAM) for the diagnosis of active tuberculosis in people living with HIV. Policy update (2019). 2018. Available from: https://apps.who.int/iris/bitstream/handle/ $10665 / 329479 / 9789241550604-$ eng.pdf? sequence $=$ $1 \&$ isAllowed=y\&ua $=1$

54. Warsinske H, Vashisht R, Khatri P. Host-response-based gene signatures for tuberculosis diagnosis: a systematic comparison of 16 signatures. PLoS Med. 2019;16(4):1-19.

55.• Penn-Nicholson A, Hraha T, Thompson EG, Sterling D, Mbandi SK, Wall KM, et al. Discovery and validation of a prognostic proteomic signature for tuberculosis progression: a prospective cohort study PLoS Med (2019) 16(4): e1002781. PLoS Med. 2019;16(7):e1002880. This study provides the validation of a 5-protein prognostic proteomic signature in a cohort study showing promising results for its further clinical implementation.

56. Soundararajan L, Kambli P, Priyadarshini S, Let B, Murugan S, Iravatham $\mathrm{C}$, et al. Whole genome enrichment approach for rapid detection of Mycobacterium tuberculosis and drug resistance- associated mutations from direct sputum sequencing. Tuberculosis. 2020 Mar 1;121:101915.

57. Cohen KA, Manson AL, Desjardins CA, Abeel T, Earl AM. Deciphering drug resistance in Mycobacterium tuberculosis using whole-genome sequencing: progress, promise, and challenges. Genome Medicine. 2019;11:1-18. BioMed Central Ltd.; [cited $2020 \mathrm{Jul}$ 30]. Available from. https://doi.org/10.1186/s13073019-0660-8.

58. Diriba G, Kebede A, Yaregal Z, Getahun M, Tadesse M, Meaza A, et al. Performance of Mycobacterium Growth Indicator Tube BACTEC 960 with Lowenstein-Jensen method for diagnosis of Mycobacterium tuberculosis at Ethiopian National Tuberculosis Reference Laboratory, Addis Ababa, Ethiopia. BMC Res Notes. 2017;10(1):181 [cited $2020 \mathrm{Jul}$ 29]. Available from:/pmc/articles/ PMC5424417/?report=abstract.

59. Mekonnen B, Mihret A, Getahun M, Hailu T, Sidiki SV, Kelley $\mathrm{H}$, et al. Evaluation of the tuberculosis culture color plate test for rapid detection of drug susceptible and drug-resistant Mycobacterium tuberculosis in a resource-limited setting, Addis Ababa, Ethiopia. PLoS One. 2019;14(5):e0215679 Ehtesham HS, editor. [cited $2020 \mathrm{Jul} 29$ ]. Available from: https://dx.plos.org/10. 1371/journal.pone.0215679.

60. Shibabaw A, Gelaw B, Kelley HV, Tesfaye E, Miquel BaladaLlasat J, Evans CA, et al. MDR/XDR-TB Colour Test for drug susceptibility testing of Mycobacterium tuberculosis, Northwest Ethiopia. Int J Infect Dis. 2020 [cited 2020 Jan 8]; Available from;90:213-8. https://doi.org/10.1016/j.ijid.2019.10.041.

61. Mohr E, Ferlazzo G, Hewison C, De Azevedo V, Isaakidis P. Bedaquiline and delamanid in combination for treatment of drug-resistant tuberculosis. Lancet Infect Dis. 2019;19:470. Lancet Publishing Group; [cited 2020 Sep 15]. Available from. https://doi.org/10.1016/S1473-

62. Ballif M, Renner L, Dusingize JC, Leroy V, Ayaya S, WoolsKaloustian K, et al. Tuberculosis in pediatric antiretroviral therapy programs in low- and middle-income countries: diagnosis and screening practices. J Pediatric Infect Dis Soc. 2015;4(1):30-8.

63. Hamada Y, Lujan J, Schenkel K, Ford N, Getahun H. Sensitivity and specificity of WHO's recommended four-symptom screening rule for tuberculosis in people living with HIV: a systematic review and meta-analysis. Lancet HIV. 2018;5(9):e515-23. Available from. https://doi.org/10.1016/S2352-3018(18)30137-1.

64. World Health Organization. Meeting Report of a Technical Expert Consultation : non-inferiority analysis of Xpert MTB/RIF Ultra compared to Xpert MTB/RIF; 2017. p. 1-11. Lancet Publishing Group; [cited 2020 Sep 15]. Available from: http://apps.who.int/bookorders

65. Shete PB, Farr K, Strnad L, Gray CM, Cattamanchi A. Diagnostic accuracy of TB-LAMP for pulmonary tuberculosis: a systematic review and meta-analysis. BMC Infect Dis. 2019;19(1):1-11.

66. García-Basteiro AL, DiNardo A, Saavedra B, Silva DR, Palmero D, Gegia M, et al. Point of care diagnostics for tuberculosis. Rev Port Pneumol (English Ed). 2018;24(2):73-85. Available from. https://doi.org/10.1016/j.rppnen.2017.12.002.

67. WHO WHO. The use of lateral flow urine lipoarabinomannan assay (LF-LAM) for diagnosis and screening of active TB in people living with HIV, policy guidance. 2015. Available from: https://apps.who. int/iris/bitstream/handle/10665/112472/9789241506335_eng.pdf; jsessionid=7D2DFDE3AED965F3D6750B7B8F194E77? sequence $=1$

68. García JI, Kelley HV, Meléndez J, de León RAA, Castillo A, Sidiki S, et al. Improved Alere Determine Lipoarabinomannan Antigen Detection Test for the diagnosis of human and bovine tuberculosis by manipulating urine and milk. Sci Rep. 2019;9(1):18012.

69.• Broger T, Reipold I, Ongarello S, Mbchb S, Mbchb S, Mbchb AW, et al. Novel lipoarabinomannan point-of-care tuberculosis test for people with HIV: a diagnostic accuracy study. Artic 
Lancet Infect Dis. 2019;19:852-61. [cited 2020 Jan 22]. Available from: https://www.finddx.org/. This diagnostic accuracy study of a novel LAM test uses a couple of high affinity monoclonal antibodies against specific LAM epitopes providing a substantial increase in sensitivity.

70. Lionex | Diagnostics and Therapeutics. 89-100. [cited 2020 Sep 15]. Available from: https://lionex.de/

71. Darboe F, Mbandi SK, Naidoo K, Yende-Zuma N, Lewis L, Thompson EG, et al. Detection of tuberculosis recurrence, diagnosis and treatment response by a blood transcriptomic risk signature in HIV-infected persons on antiretroviral therapy. Front Microbiol. 2019;10:1-16.

72. Broger T, Sossen B, du Toit E, Kerkhoff AD, Schutz C, Ivanova Reipold E, et al. Novel lipoarabinomannan point-of-care tuberculosis test for people with HIV: a diagnostic accuracy study. Lancet Infect Dis. 2019;19(8):852-61 [cited 2020 Jul 30]; Available from: https://www.finddx.org/.

73. Esmail H, Cobelens F, Goletti D. Transcriptional biomarkers for predicting development of tuberculosis: progress and clinical considerations. Eur Respir J. 2020;55(3):5-9. Available from. https:// doi.org/10.1183/13993003.01957-2019.

74. Pankhurst LJ, del Ojo EC, Votintseva AA, Walker TM, Cole K, Davies J, et al. Rapid, comprehensive, and affordable mycobacterial diagnosis with whole-genome sequencing: a prospective study. Lancet Respir Med. 2016;4(1):49-58. Available from. https://doi.org/10.1016/S2213-2600(15)00466-X.

75. Cole ST. Comparative and functional genomics of the Mycobacterium tuberculosis complex. Microbiology. 2002;148(10):2919-28. For the first time, this outstanding paper deciphers the complete genome of the Mycobacterium tuberculosis reference strain $\mathrm{H}_{37} \mathrm{Rv}$.

76. Zak DE, Penn-Nicholson A, Scriba TJ, Thompson E, Suliman S, Amon LM, et al. A blood RNA signature for tuberculosis disease risk: a prospective cohort study. Lancet. 2016;387(10035):231222. [cited $2020 \mathrm{Jul}$ 2]; Available from. https://doi.org/10.1016/ S0140-6736(15)01316-1.

77. Chen X, He G, Wang S, Lin S, Chen J, Zhang W. Evaluation of whole-genome sequence method to diagnose resistance of 13 antituberculosis drugs and characterize resistance genes in clinical multi-drug resistance mycobacterium tuberculosis isolates from China. Front Microbiol. 2019;10 [cited 2020 Jul 30]. Available from: https://pubmed.ncbi.nlm.nih.gov/31417530/.

78. Schmidt K, Mwaigwisya S, Crossman LC, Doumith M, Munroe D, Pires $\mathrm{C}$, et al. Identification of bacterial pathogens and antimicrobial resistance directly from clinical urines by nanopore-based metagenomic sequencing. J Antimicrob Chemother. 2017;72(1): 104-14.

79. Votintseva AA, Bradley P, Pankhurst L, Del Ojo Elias C, Loose M, Nilgiriwala K, et al. Same-day diagnostic and surveillance data for tuberculosis via whole-genome sequencing of direct respiratory samples. J Clin Microbiol. 2017;55(5):1285-98. In this study, a low cost DNA extraction method is used for WGS directly from sputum smear positive clinical samples; sequencing was performed using the illumina MiSeq sequencer and Mycobacterium tuberculosis was identified in all samples in which DNA extraction was successful in less than 2 days.

80. Soundararajan L, Kambli P, Priyadarshini S, Let B, Murugan S, Iravatham $\mathrm{C}$, et al. Whole genome enrichment approach for rapid detection of Mycobacterium tuberculosis and drug resistanceassociated mutations from direct sputum sequencing. Tuberculosis. 2020;121:101915 [cited 2020 Aug 24]. Available from: https://linkinghub.elsevier.com/retrieve/pii/ S1472979219302975.

81. Meehan CJ, Goig GA, Kohl TA, Verboven L, Dippenaar A, Ezewudo $M$, et al. Whole genome sequencing of Mycobacterium tuberculosis: current standards and open issues.
Nature Rev Microbiol. 2019;17:533-45 Nature Publishing Group; [cited $2020 \mathrm{Jul}$ 30]. Available from: https:/www.nature.com/ articles/s41579-019-0214-5.

82. Moliva JI, Turner J, Torrelles JB. Prospects in Mycobacterium bovis Bacille Calmette et Guérin (BCG) vaccine diversity and delivery: why does BCG fail to protect against tuberculosis? Vaccine. 2015;33:5035-41 Elsevier Ltd; [cited 2020 Jul 22]. Available from: https://pubmed.ncbi.nlm.nih.gov/26319069/.

83. Moliva JI, Turner J, Torrelles JB. Immune responses to bacillus Calmette-Guérin Vaccination: why do they fail to protect against Mycobacterium tuberculosis? Front Immunol. 2017;8 Available from: http://journal.frontiersin.org/article/10.3389/fimmu.2017. 00407/full.

84. Andersen P, Doherty TM. The success and failure of BCG - implications for a novel tuberculosis vaccine. Nature Rev Microbiol. 2005;3:656-62 Nature Publishing Group; [cited 2020 Jul 9]. Available from: www.nature.com/reviews/micro.

85.• Nemes E, Geldenhuys H, Rozot V, Rutkowski KT, Ratangee F, Bilek $\mathrm{N}$, et al. Prevention of M. tuberculosis infection with $\mathrm{H} 4$ :IC31 vaccine or BCG revaccination. N Engl J Med. 2018;379(2):138-49. This phase 2 trial provides proof of concept that the subunit TB vaccine H4:IC31 is effective in preventing Mycobacterium tuberculosis infection in a high-transmission setting

86.•• Tait DR, Hatherill M, Van Der Meeren O, Ginsberg AM, Van Brakel E, Salaun B, et al. Final analysis of a trial of M72/AS01E vaccine to prevent tuberculosis. N Engl J Med. 2019;381(25): 2429-39. The M72/AS01E candidate vaccine provides proof of concept that a TB vaccine is able to proctect against progression to pulmonary TB for at least 3 years with a vaccine of 49.7\% and a $90 \%$ confidence interval of 12.1 to $71.2 \%$.

87. World Health Organization (WHO). Preferred Product Characteristics for New Tuberculosis Vaccines. 2018. Available from: http://apps.who.int/iris/bitstream/handle/10665/273089/ WHO-IVB-18.06-eng.pdf

88. Knight GM, Griffiths UK, Sumner T, Laurence YV, Gheorghe A, Vassall A, et al. Impact and cost-effectiveness of new tuberculosis vaccines in low- and middle-income countries. Proc Natl Acad Sci U S A. 2014;111(43):15520-5.

89. Harris RC, Sumner T, Knight GM, White RG. Systematic review of mathematical models exploring the epidemiological impact of future TB vaccines, vol. 12; 2016 [cited 2020 Jun 11]; Available from. p. 2813-32. https://doi.org/10.1080/21645515.2016.1205769.

90. Sable SB, Posey JE, Scriba TJ. Tuberculosis Vaccine Development: Progress in Clinical Evaluation. Clin Microbiol Rev. 2019;33(1).

91. McShane H. Insights and challenges in tuberculosis vaccine development. Lancet Respir Med. 2019;7(9):810-9. [cited 2020 Jul 6]. Available from. https://doi.org/10.1016/S2213-2600(19)30274-7.

92. Netea MG, Joosten LAB, Latz E, Mills KHG, Natoli G, Stunnenberg HG, et al. Trained immunity: a program of innate immune memory in health and disease. Science. 2016;352:427. American Association for the Advancement of Science; [cited 2020 Aug 7]. Available from. https://doi.org/10.1126/science.aaf1098.

93. Lerm M, Netea MG. Trained immunity: a new avenue for tuberculosis vaccine development. J Intern Med. 2016;279(4):337-46.

94. Arcos J, Sasindran SJ, Fujiwara N, Turner J, Schlesinger LS, Torrelles JB. Human lung hydrolases delineate mycobacterium tuberculosis -macrophage interactions and the capacity to control infection. J Immunol. 2011;187(1):372-81.

95. Ferguson JS, Weis JJ, Martin JL, Schlesinger LS. Complement Protein C3 Binding to Mycobacterium tuberculosis is initiated by the classical pathway in human bronchoalveolar lavage fluid. Infect Immun. 2004;72(5):2564-73 [cited 2020 Sep 15]; Available from: https://pubmed.ncbi.nlm.nih.gov/15102764/.

96. Jacobs AJ, Mongkolsapaya J, Screaton GR, McShane H, Wilkinson RJ. Antibodies and tuberculosis. Tuberculosis. 
2016;101:102-13. Available from. https://doi.org/10.1016/j.tube. 2016.08.001.

97. Torrado E, Fountain JJ, Robinson RT, Martino CA, Pearl JE, RangelMoreno J, et al. Differential and site specific impact of B cells in the protective immune response to Mycobacterium tuberculosis in the mouse. PLoS One. 2013;8(4):61681 [cited 2020 Jul 28]; Available from: /pmc/articles/PMC3627912/?report=abstract.

98. Hamasur B, Haile M, Pawlowski A, Schröder U, Källenius G, Svenson SB. A mycobacterial lipoarabinomannan specific monoclonal antibody and its $\mathrm{F}\left(\mathrm{ab}^{\prime}\right) 2$ fragment prolong survival of mice infected with Mycobacterium tuberculosis. Clin Exp Immunol. 2004;138(1):30-8 [cited $2020 \mathrm{Jul}$ 28]; Available from: /pmc/articles/PMC1809178/?report=abstract.

99. Montamat-Sicotte DJ, Millington KA, Willcox CR, HingleyWilson S, Hackforth S, Innes J, et al. A mycolic acid-specific CD1-restricted $\mathrm{T}$ cell population contributes to acute and memory immune responses in human tuberculosis infection. J Clin Invest. 2011;121(6):2493-503 [cited 2020 Jul 28]; Available from: /pmc/ articles/PMC3104771/?report=abstract.

100. Harriff MJ, McMurtrey C, Froyd CA, Jin H, Cansler M, Null M, et al. MR1 displays the microbial metabolome driving selective MR1-restricted T cell receptor usage. Sci Immunol. 2018;3(25) [cited 2020 Jul 28]. Available from: https://immunology. sciencemag.org/content/3/25/eaao2556.

101. van Meijgaarden KE, Haks MC, Caccamo N, Dieli F, Ottenhoff THM, Joosten SA. Human CD8+ T-cells recognizing peptides from Mycobacterium tuberculosis (Mtb) presented by HLA-E have an unorthodox Th2-like, multifunctional, Mtb inhibitory phenotype and represent a novel human T-cell subset. PLoS Pathog. 2015;11(3):1-24 [cited 2020 Jul 28]; Available from: /pmc/articles/PMC4372528/?report=abstract.

102. Suliman S, Murphy M, Musvosvi M, Gela A, Meermeier EW, Geldenhuys H, et al. MR1-independent activation of human mucosal-associated invariant $\mathrm{T}$ cells by Mycobacteria. J Immunol. 2019;203(11):2917-27 [cited 2020 Sep 15]; Available from: http://www.jimmunol.org/content/203/11/2917.

103. Joosten SA, Ottenhoff THM, Lewinsohn DM, Hoft DF, Moody DB, Seshadri C. Harnessing donor unrestricted T-cells for new vaccines against tuberculosis. Vaccine. 2019;37(23):3022-30. Available from. https://doi.org/10.1016/j.vaccine.2019.04.050.

104. Schrager LK, Harris RC, Vekemans J. Research and development of new tuberculosis vaccines: a review. F1000Res. 2018;7:1732.

105. Nagpal PS, Kesarwani A, Sahu P, Upadhyay P. Aerosol immunization by alginate coated mycobacterium (BCG/MIP) particles provide enhanced immune response and protective efficacy than aerosol of plain mycobacterium against M.tb. H37Rv infection in mice. BMC Infect Dis. 2019;19(1):1-14.

106. Aguilo N, Uranga S, Mata E, Tarancon R. Respiratory immunization with a whole cell inactivated vaccine induces functional mucosal immunoglobulins against tuberculosis in mice and non-human primates. Front Microbiol. 2020;11(June):1-15.

107. Moliva JI, Hossfeld AP, Sidiki S, Canan CH, Dwivedi V, Beamer $\mathrm{G}$, et al. Selective delipidation of Mycobacterium bovis BCG enables direct pulmonary vaccination and enhances protection against Mycobacterium tuberculosis. Mucosal Immunol. 2019;12(3):805-15. Available from: https://doi.org/10.1038/ s41385-019-0148-2. This study shows that selective BCG delipidation removes inflammatory lipids while keeping BCG viable and also increases protection against Mycobacterium tuberculosis infection in mice.

108. Diego-Gonzalez L, Crecente-Campo J, Paul MJ, Singh M, Reljic $\mathrm{R}$, Alonso MJ, et al. Design of Polymeric Nanocapsules for Intranasal Vaccination against Mycobacterium Tuberculosis: Influence of the Polymeric Shell and Antigen Positioning. Pharmaceutics. 2020;12(6):1-22.
109. Sheikh JA, Ehtesham NZ, Hasnain SE. Revisiting BCG to control tuberculosis: mucosal delivery and delipidation? Lancet Infect Dis. 2020;20(3):272-3. Available from. https://doi.org/10.1016/ S1473-3099(19)30702-9.

110. Gheibi Hayat SM, Darroudi M. Nanovaccine: A novel approach in immunization. J Cell Physiol. 2019;234(8):12530-6.

111. Thukral A, Ross K, Hansen C, Phanse Y, Narasimhan B, Steinberg $\mathrm{H}$, et al. A single dose polyanhydride-based nanovaccine against paratuberculosis infection. npj Vaccines. 2020;5(1):1-10. [cited $2020 \mathrm{Jul}$ 31]. Available from. https://doi. org/10.1038/s41541-020-0164-y.

112. Corbett KS, Flynn B, Foulds KE, Francica JR, Boyoglu-Barnum S, Werner AP, et al. Evaluation of the mRNA-1273 vaccine against SARS-CoV-2 in nonhuman primates. N Engl J Med. 2020:1-12 Available from: http://www.ncbi.nlm.nih.gov/pubmed/32722908.

113. Beissert T, Perkovic M, Vogel A, Erbar S, Walzer KC, Hempel T, et al. A trans-amplifying RNA vaccine strategy for induction of potent protective immunity. Mol Ther. 2019;28(1) [cited 2020 Aug 3] Available from: https://pubmed.ncbi.nlm.nih.gov/31624015/.

114. Lorenzi JCC, Trombone APF, Rocha CD, Almeida LP, Lousada RL, Malardo T, et al. Intranasal vaccination with messenger RNA as a new approach in gene therapy: use against tuberculosis. BMC Biotechnol. 2010;10(1):77 [cited 2020 Jun 23]. Available from: http:// bmcbiotechnol.biomedcentral.com/articles/10.1186/1472-6750-10-77.

115. Coler, Rhea \& Fletcher H. Development of an RNA based vaccine against Mycobacterium tuberculosis | The VALIDATE Network. [cited 2020 Aug 4]. Available from: https://www.validatenetwork.org/development-of-an-rna-based-vaccine-againstmycobacterium-tuberculosis

116. McShane H. Controlled human infection models: is it really feasible to give people tuberculosis? Am J Respir Crit Care Med. 2020;201(10):1180-1. Available from. https://doi.org/10.1164/ rccm.201912-2408ED.

117. Harris SA, Meyer J, Satti I, Marsay L, Poulton ID, Tanner R, et al. Evaluation of a human BCG challenge model to assess antimycobacterial immunity induced by BCG and a candidate tuberculosis vaccine, MVA85A, alone and in combination. J Infect Dis. 2014;209(8):1259-68. In this study, healthy adults BCG naïve and previously BCG vaccinated are challenged with intradermal BCG as a surrogate for human Mycobacterium tuberculosis challenge. This model is able to detect anti-mycobacterial immunity induced by vaccination

118. Minhinnick A, Harris S, Wilkie M, Peter J, Stockdale L, ManjalyThomas ZR, et al. Optimization of a human bacille calmetteguérin challenge model: A tool to evaluate antimycobacterial immunity. J Infect Dis. 2015;212(11):824-30.

119. Davids M, Pooran A, Hermann C, Mottay L, Thompson F, Cardenas J, et al. A human lung challenge model to evaluate the safety and immunogenicity of PPD and Live Bacillus CalmetteGuérin. Am J Respir Crit Care Med. 2020;201(10):1277-91.

120. Moorlag SJCFM, Arts RJW, van Crevel R, Netea MG. Nonspecific effects of BCG vaccine on viral infections. Clin Microbiol Infect. 2019;25(12):1473-8.

121. O'Neill LAJ, Netea MG. BCG-induced trained immunity: can it offer protection against COVID-19? Nat Rev Immunol. 2020;20(6):335-7. Available from. https://doi.org/10.1038/ s41577-020-0337-y.

122. Curtis N, Sparrow A, Ghebreyesus TA, Netea MG. Considering BCG vaccination to reduce the impact of COVID-19. Lancet. 2020;395(10236):1545-6. Available from. https://doi.org/10. 1016/S0140-6736(20)31025-4.

Publisher's Note Springer Nature remains neutral with regard to jurisdictional claims in published maps and institutional affiliations. 